\title{
One-step microalgal biodiesel production from Chlorella pyrenoidosa using subcritical methanol extraction (SCM) technology
}

\begin{abstract}
In this work, we propose a one-step subcritical methanol extraction (SCM) process for biodiesel production from Chlorella pyrenoidosa. Therefore, the present study attempts to establish and determine the optimum operating conditions for maximum biodiesel yield from SCM of C. pyrenoidosa. A statistical approach, i.e. response surface methodology is employed in this study. The effects of three operational factors: reaction temperature $\left(140-220^{\circ} \mathrm{C}\right)$, reaction time (1-15 $\mathrm{min}$ ) and methanol to algae ratio (1-9 wt.\%) were investigated using a central composite design. A maximum yield of crude biodiesel of $7.1 \mathrm{wt} . \%$ was obtained at $160{ }^{\circ} \mathrm{C}, 3 \mathrm{~min}$ reaction time and $7 \mathrm{wt} . \%$ methanol to algae ratio. The analysis of variance revealed that methanol to algae ratio is the most significant factor for maximizing biodiesel yield. Regression analysis showed a good fit of the experimental data to the second-order polynomial model. With no requirement of catalyst nor any pretreatment step, SCM process is economically feasible to scale up the commercial biodiesel production from algae.
\end{abstract}

Keyword: Low-lipid algae; Reaction temperature; Reaction time; Methanol to algae ratio; Central composite design; Response surface methodology 